\title{
Early treated hypothyroidism: development at 3 years
}

\author{
G MURPHY, J A HULSE, D JACKSON, P TYRER, J GLOSSOP, I SMITH, AND D GRANT \\ Institute of Child Health and Department of Paediatrics, St Thomas's Hospital, London
}

SUMmary Eighty children from the North West and North East Thames Regional Health Authorities who had been identified as having congenital hypothyroidism either by neonatal screening (76 cases) or by clinical symptoms (four) were seen for psychological assessments at 1 (60 cases), 3 (58), and/or 5 (20) years of age. Almost all the children's scores were in the normal range, and comparisons with matched controls suggested that they were doing only slightly less well than normal children in overall development. They were significantly slower, however, on a motor skills task. Moreover, a low initial serum thyroxine and triiodothyronine value, considerable delay in initial bone age, and an absence of thyroid tissue on isotope scan seemed to be associated with a somewhat poorer prognosis.

Over the last few years many countries have set up neonatal screening programmes for the'detection of congenital hypothyroidism. It had been anticipated that early recognition and treatment of congenital hypothyroidism would ameliorate the adverse psychological sequelae of delay in starting treatment, ${ }^{1-4}$ and recent reports from a number of centres have provided evidence that this is the case $^{5-9}$ We present a progress report on 80 infants, 76 of whom had been detected in the neonatal screening programme for the North East and North West Thames Regions of the United Kingdom, which was introduced on a pilot basis and funded by the Medical Research Council, between August 1978 and the end of December 1981. An additional four patients were detected because of symptoms, having been missed in the screening programme. The 80 children form the pilot cohort in a national epidemiological project set up to monitor the introduction of nationwide screening for congenital hypothyroidism. Findings reported here will be used to plan the assessments for children on the national register when they reach 5 years.

\section{Patients and methods}

Neonatal screening for congenital hypothyroidism, based on dried blood spot thyroid stimulating hormone, began in the two North Thames Health Regions in August $1978,{ }^{1011}$ as part of their Regional Neonatal Screening Services (Director Professor M Hjelm, Department of Clinical Biochemistry, Institute of Child Health, London). By the end of December 1981 over 300000 infants had been screened and 77 cases of congenital hypothyroidism identified. One of these was subsequently shown to have transient hypothyroidism ${ }^{6}$ and has been excluded from analysis. Of the remaining 76 patients, 67 were first detected by screening, two were diagnosed on the basis of symptoms before the screening result was obtained, and in seven a clinical diagnosis was made on the same day as the positive result of the screening test became available. In addition to the cases identified by screening, four children presented between 59 and 163 days of age with clinical features of hypothyroidism. In one the Guthrie card had been lost in transit to the laboratory and in another, in whom the result of the screening test had been positive, was not traced because of changes of both name and address. Two were missed because the screening test gave false negative results for technical reasons. Adjustments have since been made to the techniques used.

At the initial hospital visit the number of symptoms was recorded, together with other clinical data and various tests of thyroid function, including plasma thyroxine (79 cases), assay of thyroid stimulating hormone (65), plasma triiodothyronine (35), estimation of bone age (63), and thyroid isotope scan (51). ${ }^{1012}$ Ten patients $(15 \%)$ who had estimation of thyroid stimulating hormone performed showed concentrations above $1000 \mathrm{mU} / \mathrm{l}$, and 21 patients $(27 \%)$ who had assay of thyroxine performed showed concentrations below $20 \mathrm{nmol} / \mathrm{l}(1.55 \mu \mathrm{g} / 100$ $\mathrm{ml}) ; 26(33 \%)$ had values above $60 \mathrm{nmol} / \mathrm{l}(4.66$ $\mu \mathrm{g} / 100 \mathrm{ml}$ ). Seven patients had athyrosis on the 
isotope scan, 30 had ectopic glands, and in 14 the thyroid was normally sited.

Children usually began thyroid replacement therapy immediately after the initial hospital visit. The mean (SD) age at start of treatment of cases diagnosed on screening was $27(7 \cdot 6)$ days after one patient who started treatment late had been excluded. In this child treatment was delayed until 57 days because of borderline evidence of hypothyroidism.

Between birth and 5 years follow up data were collected yearly with regard to general health, growth, L-thyroxine dosage, and tests of thyroid function. Much of this information was supplied by the local paediatricians who supervised the children's day to day care. In 49 of the children the diagnosis of congenital hypothyroidism had been confirmed by temporary withdrawal of treatment at the age of 1 year. $^{6}$

Psychological assessments. At 1 year of age 58 children were tested on the Griffiths scale. Some of these results have already been reported by Hulse $e t$ al. ${ }^{6}$ Patients were recalled at the age of 3 years for assessment on the McCarthy scales of children's abilities and Richman's behavioural screening questionnaire, ${ }^{13}$ except for 18 patients who were already over 3 years before testing began. A test of speeded motor skills (Wallin B pegboard from the Merrill-Palmer scale) was also given. Children were recalled again at 5 years of age for assessment on the Weschler preschool and primary scale of intelligence. A shortened, adapted form of the Bruininsks-Oseretsky test of motor proficiency ${ }^{14}$ and Richman's behavioural screening questionnaire (check list form $)^{15}$ were also given, together with a brief family background questionnaire.

Control groups of 3 and 5 year old normal children matched for age, sex, race, social class, and also spoken language are still being obtained from the general practice registers of family doctors in north London and are being assessed for comparison with the hypothyroid children. Results are presented here on 40 matched control children (aged 3 years).

\section{Results}

Tests at 1 year. Of the 60 children who were seen for assessment at 1 year, the findings in 36 have already been reported. ${ }^{6}$ All but two of the 60 children were tested on the Griffiths scale, one child being unwell when seen and the parents of one child refusing assessment. The results are given in Table 1 . Although no control group was tested, the developmental quotients are clearly in the normal range compared with recent samples of normal British children. ${ }^{16}$ There are no significant associations between the developmental quotients and the number of symptoms when first seen, the age at which treatment was started, or the initial results for bone age and serum thyroxine, triiodothyronine, and thyroid stimulating hormone concentrations. The children with athyrosis and those with probable dyshormonogenesis did as well as the children with ectopic glands. Only two of the children had developmental quotients below 90; one was an athyrotic child with cerebral gigantism (Soto's syndrome $)^{17}$ and the other was a child with dyshormonogenesis who was undertreated at the age of 1 year (thyroid stimulating hormone $214 \mathrm{mu} / \mathrm{l}$; thyroxine $72 \mathrm{nmol} / \mathrm{l}(5.59 \mu \mathrm{g} / 100 \mathrm{ml}))$. A third child with multiple congenital abnormalities who was known to be doing badly was lost to follow up. Developmental quotients for the children still on $25 \mu \mathrm{g}$ L-thyroxine daily ( 25 cases) did not differ significantly from those children on $50 \mu \mathrm{g}$ L-thyroxine daily. This was also true for children on less than $3 \mu \mathrm{g} / \mathrm{kg} / \mathrm{day}$ compared with those on higher daily doses.

Tests at 3 years. Testing at 3 years did not begin until May 1982 when 18 out of the sample of 80 were already aged over 3 . Of the next 62 consecutive cases, results are available in 58 (three children had left the country and one had moved away from London). The mean (SD) scores on the short form of the McCarthy scales ${ }^{18}$ are given in Table 2 . The results for 48 children tested on the full McCarthy scales are almost identical.

The scores for the short form McCarthy scales do not differ significantly from the 1971 standardisa-

Table 1 Development quotients at 1 year of age in 58 cases tested on the Griffiths scales

\begin{tabular}{lllllll}
\hline & Quotient & & & & \\
\cline { 2 - 7 } & Developmental & Locomotor & $\begin{array}{l}\text { Personal } \\
\text { social }\end{array}$ & $\begin{array}{l}\text { Hearing } \\
\text { speech }\end{array}$ & Eye hand & Performance \\
\hline Mean & 104 & 106 & 101 & 101 & 104 & 107 \\
SD & 7.7 & 11.0 & 7.8 & 9.5 & 9.2 & 14.1 \\
\hline
\end{tabular}


Table 2 Outcome of testing with McCarthy short form and Wallin B pegboard at 3 years in 58 children with congenital hypothyroidism

\begin{tabular}{|c|c|c|c|c|c|c|}
\hline & \multicolumn{3}{|c|}{ Short form McCarthy general cognitive indexes* } & \multicolumn{3}{|c|}{ Pegboard speed (secs) } \\
\hline & No & Mean & $S D$ & No & Mean & $S D$ \\
\hline All cases tested so far & 57 & 102 & $15 \cdot 1$ & 55 & $20 \cdot 4$ & 6.8 \\
\hline Matched cases only & 39 & $103 \cdot 6$ & $13 \cdot 7$ & 36 & $19 \cdot 6$ & $6 \cdot 5$ \\
\hline Matched controls & 39 & $105 \cdot 8$ & $11 \cdot 3$ & 36 & $16 \cdot 5$ & $3 \cdot 5$ \\
\hline
\end{tabular}

* One case spoke insufficient English for a short form general cognitive index to be calculated.

Table 3 Cognitive ability at 3 years: relation between short form McCarthy general cognitive indexes and initial serum thyroxine and triiodothyronine concentrations

\begin{tabular}{|c|c|c|}
\hline & No & Mean (SD) \\
\hline \multicolumn{3}{|c|}{ Initial thyroxine: } \\
\hline$<20 \mathrm{nmol} / \mathrm{l}$ & 16 & $94(11)$ \\
\hline$>60 \mathrm{nmol} / \mathrm{l}$ & 20 & $106(18)$ \\
\hline \multicolumn{3}{|c|}{ Initial triiodothyronine: } \\
\hline$\leqslant 2 \mathrm{nmol} / \mathrm{l}$ & 15 & $93(10)$ \\
\hline$>2 \mathrm{nmol} / \mathrm{l}$ & 20 & $105(14)$ \\
\hline
\end{tabular}

Conversion: SI to traditional units-Thyroxine: $1 \mathrm{nmol} / \mathrm{l} \approx 0.077 \mu \mathrm{mol} / \mathrm{l}$.

tion sample of American children. The mean scores for the children who have matched controls shows a small but not significant difference between the two groups $(t=0.95, p=0 \cdot 35)$. The mean score for these control children is similar to that obtained in a previous large sample of British children. ${ }^{19}$

At 3 years there were no significant associations between the McCarthy general cognitive index (short form) and the mode of diagnosis (screening $v$ symptoms), the age at start of treatment, the number of initial symptoms, or serum thyroid stimulating hormone concentration. Children who had low initial thyroxine or low initial triiodothyronine concentrations tended, however, to do less well than those with higher initial concentrations (Table 3). Those with very delayed initial bone age ( $<30$ weeks) also did relatively poorly, and athyrotic children obtained lower means general cognitive indexes than those with ectopic or normally sited glands. Only two of these differences were significant, however: the children with an initial thyroxine concentration below $20 \mathrm{nmol} / \mathrm{l}$ did significantly less well than those with a concentration of $60 \mathrm{nmol} / \mathrm{l}$ or more $(\mathrm{t}=2 \cdot 6, \mathrm{p}=0.013$ by two tailed $t$ test $)$ and those with an initial triiodothyronine concentration $<2$ $\mathrm{nmol} / \mathrm{l}$ did significantly less well than those with a concentration $>2 \mathrm{nmol} / \mathrm{l}(\mathrm{t}=2.88, \mathrm{p}<0.01$ by two tailed $t$ test).

Of the 58 children tested, only one had a score more than 2 SD below the mean general cognitive index; this was an athyrotic child from a family who did not speak English whose McCarthy scores may have underestimated her ability. In addition, the child with multiple abnormalities who was lost to follow up was thought to be doing poorly.

On the test of speeded motor skills (the Wallin pegboard B from the Merrill-Palmer scale) the 55 hypothyroid children tested obtained a mean (SD) of $20 \cdot 4(6 \cdot 8)$ seconds. The control children obtained a mean (SD) of $16.6(3.5)$ seconds. The difference between the cases and their matched controls is significant (two tailed $t$ test, $\mathrm{t}=2 \cdot 46, \mathrm{p}=0.019$, $\mathrm{n}=36$ ). The effect seemed to arise from a mild clumsiness on the part of the hypothyroid children rather than a deficit in their attention.

The 56 children tested on the Richman's behavioural screening questionnaire obtained a mean (SD) score of $4.8(2 \cdot 5)$, matched cases and controls not being significantly different. Only one child had a score of more than 10 , indicating significant behaviour disturbance. This is fewer than would be expected in a normal urban population. ${ }^{20}$

Tests at 5 years. Of the initial sample of 80 children with congenital hypothyroidism, 23 have reached the age of 5 and 20 have been assessed (19 on the Weschler and one on the McCarthy scales). Of those not tested, two who have left the country were clearly in the normal range when tested at 3-4 years and the other child had multiple congenital abnormalities and had been completely lost to follow up before 1 year.

The results for the 5 year olds tested on the Weschler scale are given in Table 4. Insufficient 5 year old matched controls have been so far collected for comparison. Most scores are in the normal range. One child scored more than 2 SD below the mean (her mother had attended an educationally

Table 4 Results of the Weschler scales at 5 years in 19 children with congenital hypothyroidism

\begin{tabular}{llll}
\hline & \multicolumn{2}{l}{ Intelligence quotient } \\
\cline { 2 - 3 } & Full scale & Verbal & Performance \\
\hline Mean (SD) & $107(18)$ & $101(16)$ & $112(19)$ \\
\hline
\end{tabular}


subnormal/mild school) and only one other child scored more than one SD below the mean (the child with cerebral gigantism already mentioned). ${ }^{17}$ Another 5 year old child from an Asian family, none of whom spoke English, was not tested on the Weschler scale because of his extremely poor English. He obtained scores in the borderline range on the non-verbal sections of the McCarthy scale. $\mathrm{He}$ was one of the four cases missed on screening and the only one causing concern. He was thought to have been undertreated for much of his life in addition to late diagnosis.

\section{Discussion}

The above results indicate that at the age of 1 year children with congenital hypothyroidism who have been treated from an early age are generally within the normal range of development as reported by others. $^{7}$ (Maki I, Nose O, Harada T, et al. Followup study of treated hypothyroid infants on psychological and neurological development; Rochiccioli $\mathrm{P}$, Roge B, Alexandre F, Dutau G. A study on somatic and environmental factors of psychomotor development in 35 hypothyroids screened. Dockeray S, O'Moore M, Cahalane SF. Follow-up, psychological and developmental assessments of infants detected on neonatal screening. Papers presented at 2 nd International Conference on Neonatal Thyroid Screening, Tokyo, Japan, 1982.) Because many of the cases who presented with clinical features of congenital hypothyroidism were not tested at 1 year and a control group was not used, however, it is not possible to state that the patients with congenital hypothyroidism were completely indistinguishable from normal 1 year old children.

At the ages of 3 and 5 the children with congenital hypothyroidism were generally in the normal range for intelligence. The results for patients and matched controls suggest that they differ little in overall cognitive level from matched control subjects at 3 years, but they did significantly less well than controls in the test of speeded motor skills (Wallin B pegboard). The latter finding may indicate a minor increase in clumsiness in the patients, a common finding in children with congenital hypothyroidism who started treatment late. ${ }^{421-23}$ The behaviour of the children with congenital hypothyroidism at 3 years was not significantly different from matched controls when assessed on Richman's behavioural screening questionnaire.

Hypothyroid children with a very low initial serum thyroxine $(<20 \mathrm{nmol} / \mathrm{l})$ or low initial serum triiodothyronine $(<2.0 \mathrm{nmol} / \mathrm{l})$ have significantly lower intelligence quotients at 3 years than those with higher initial concentrations. Those with very delayed initial bone age ( $<30$ weeks) and those with absent thyroid glands also seem to be lagging slightly, though not significantly so in this small sample. These findings are consistent with results from other centres. ${ }^{724}$ Despite these effects (which may be of prenatal origin), the ability of hypothyroid children is likely to fall into the normal range, unless they have additional risk factors such as an adverse home environment or other handicapping medical condition.

A true picture of the cognitive development of early treated children with congenital hypothyroidism will only become clear when a larger group of patients and matched controls have been tested. To examine the effect of the large number of variables that may affect the children's intellectual and motor development a study of a national sample of children with congenital hypothyroidism is planned. Roughly 500 children born between January 1982 and December 1984 have been notified to the Medical Research Council Register of Children with Congenital Hypothyroidism. The aim will be to assess these patients, along with classroom controls, when they reach the age of 5 .

The project was supported by a grant from the Medical Research Council. We are very grateful to all the children and parents who have taken part in this study and to the north London general practitioners and the many helpful paediatricians who have supplied us with follow up data. We also acknowledge the help and advice of Professor Philip Graham and Dr Richard Lansdown, Department of Psychological Medicine, Hospital for Sick Children, London.

\section{References}

1 Smith DW, Blizzard RM, Wilkins L. The mental prognosis in hypothyroidism of infancy and childhood. Pediatrics 1957; 19:1011-22.

2 Raiti S, Newns GH. Cretinism: early diagnosis and its relation to mental prognosis. Arch Dis Child 1971;46:692-5.

${ }^{3}$ Klein AH, Meltzer S, Kenney FM. Improved prognosis of congenital hypothyroidism treated before 3 months. J Pediatr 1972;81:912-3.

${ }^{4}$ Hulse JA. Outcome for congenital hypothyroidism. Arch Dis Child 1984;59:23-30.

5 New England Congenital Hypothyroidism Collaborative. Effects of neonatal screening for hypothyroidism: prevention of mental retardation by treatment before clinical manifestations. Lancet 1981;ii:1095-8.

${ }^{6}$ Hulse JA, Grant DB, Jackson D, Clayton BE. Growth development and reassessment of hypothyroid infants diagnosed by screening. $\mathrm{Br}$ Med $J$ 1982;284:1435-7.

7 Glorieux J, Dussault JH, Letarte J, Guyda H, Morisette J. Preliminary results on the mental development of hypothyroid infants detected by the Quebec screening programme. J Pediatr 1983;102:19-22.

${ }^{8}$ New England Congenital Hypothyroidism Collaborative Characteristics of infantile hypothyroidism discovered on neonatal screening. $J$ Pediatr 1984;104:539-44.

9 Barnes ND. Screening for congenital hypothyroidism: the first decade. Arch Dis Child 1985;60:587-92. 
${ }^{10}$ Hulse JA, Grant DB, Clayton BE, et al. Population screening for congenital hypothyroidism. Br Med J 1980;280:675-8.

1 Edwards RWH, Hulse JA, Jackson D, Spracklan A, Clayton BE. Programming and running radioimmune assay in the L-TSH screening procedure using dried blood spots and the NE 1600 Gamma Counter on line to the HP 9815 S calculator. Ann Clin Biochem 1980;17:122-9.

12 Pyle SI, Hoerr NL. A radiographic standard of reference for the growing knee. New York: Charles C Thomas, 1969.

13 Richman N, Graham P. A behavioural screening questionnaire for use with three year old children: preliminary findings. Journal of Child Psychology 1975;12:5-33.

14 Bruininsks RH. Bruininsks-Oseretsky test of motor proficiency. Minnesota: American Guidance Service, 1978.

15 Richman N. Is a behavioural check-list for preschool children useful? In: Graham P, ed. Epidemiological approaches in child psychiatry. London: Academic Press, 1977.

16 Hansen R, Aldridge Smith J, Hume W. Achievements of infants on items of the Griffiths scales. Child: care, health, and development. (In press.)

${ }^{17}$ Hulse JA. Two children with cerebral gigantism and congenital primary hypothyroidism. Dev Med Child Neurol 1981;23:242-6.

18 Kaufman AS. A McCarthy short form for rapid screening of preschool, kindergarten and first grade children. Contemporary Educational Psychology 1977;2:149-57.
${ }^{19}$ Lynch A, Mitchell LB, Vincent EM, Trueman LB, MacDonald L. The McCarthy scales of children's abilities: a normative study on English 4 year olds. Br J Educ Psychol 1982;52:133-43.

20 Richman N, Stevenson JE, Graham PJ. Prevalence of behaviour problems in 3-year-old children: an epidemiological study in a London borough. J Child Psychol Psychiatry 1975;16:277-86.

${ }^{21}$ Hanefield F, Richer I, Weber B, Zabransky S. Neurological studies on children with hypothyroidism on long-term treatment. Acta Paediatr Scand 1974;63:332.

22 McFaul R, Dorner S, Brett EM, Grant DB. Neurological abnormalities in patients treated for hypothyroidism from early life. Arch Dis Child 1978;53:611-9.

${ }^{23}$ Birrell J, Frost GJ, Parkin JM. The development of children with congenital hypothyroidism. Dev Med Child Neurol 1983;25:512-9.

${ }^{24}$ Rovet JF, Westbrook D, Ehrlich RM. Neonatal thyroid deficiency: early temperamental and cognitive characteristics. J Amer Acad Child Psychiatry 1984;23:10-22.

Correspondence to Dr G Murphy, Department of Child Psychiatry, Hospital for Sick Children, Great Ormond Street, London WC1.

Received 18 April 1986 